\title{
RELAÇÃO FAMÍLIA-ESCOLA: experiência de uma extensão universitária com famílias de baixa renda em escolas da rede pública do município de Mamanguape/PB
}

\author{
FAMILY - SCHOOL RELATIONSHIP: \\ experience of a university extension with low income families \\ in public schools in Mamanguape / PB
}

\author{
Osicleide Lima Bezerra* \\ Ana Paula Taigy Amaral ${ }^{* *}$
}

\begin{abstract}
Resumo
O presente trabalho é fruto de reflexões resultantes de um projeto de extensão universitária, realizado em 2017, pelo Campus IV - Litoral Norte da Universidade Federal da Paraíba -, denominado "Família, escola e desenvolvimento de aprendizagem", que teve como objetivo a investigação da participação familiar no acompanhamento da aprendizagem de crianças e adolescentes matriculados no II ciclo do ensino fundamental de escolas da rede pública de ensino do Município de Mamanguape/PB. Utilizou-se o método de abordagem indutivo, desenvolvido através de uma pesquisa exploratória de estudo de caso e bibliográfica sobre a discussão e análise do tema descrito. Constatamos a dificuldade existente no âmago da relação família-escola, quando o cenário envolve famílias de baixa renda e escolas da rede pública de ensino. Concluiu-se que é possível a construção de um diálogo com as famílias dos estudantes de baixa renda, no intuito de aproximá-las do cotidiano escolar da criança/adolescente, mas que essa prática exige uma mudança de postura por parte da escola e de um trabalho em conjunto com a Secretaria de Educação, que disponibiliza recursos e dá suporte para que os profissionais da educação desenvolvam esse trabalho.
\end{abstract}

Palavras-chave: Relação Família-Escola. Aprendizagem. Baixa renda. Diálogo.

\begin{abstract}
The present work is the result of reflections resulting from a university extension project, carried out in 2017, by Campus IV - North Coast of the Federal University of Paraíba - UFPB, called "Family, school and learning development", which aimed to research of family participation in monitoring the learning of children / adolescents enrolled in the 2nd cycle of elementary school in public schools in Mamanguape - PB. We used the inductive approach method, developed through an exploratory case study and bibliographical research on the discussion and analysis of the described theme. We note the difficulty at the heart of the family - school relationship, when the scenario involves low - income families and public schools. It was concluded that it is possible to build a dialogue with the families of low-income students, in order to bring them closer to the daily life of the child / adolescent, but that this practice requires a change of attitude on the part of the school and a I work closely with the education department, which provides resources and supports education professionals to develop this work.
\end{abstract}

Keywords: Family-School Relationship. Learning. Low income. Dialogue

\footnotetext{
* Professora adjunta da Universidade Federal da Paraíba (Campus IV - Litoral Norte). Possui graduação, mestrado e doutorado em Ciências Sociais pela Universidade Federal do Rio Grande do Norte (UFRN). É líder do Grupo de Estudos Sociedade, Trabalho e Educação (CNPQ/UFPB). Coordenadora adjunta do Projeto de Extensão "Família, Escola e Aprendizagem”. E-mail: osicleide@ccae.ufpb.br.

** Mestranda em Educação pelo Programa de Pós-Graduação em Educação (PPGE) da Universidade Federal da Paraíba (UFPB). Advogada, graduada em Direito pelo Centro Universitário de João Pessoa. Graduanda em Letras (licenciatura) - Língua Portuguesa, pela UFPB. E-mail: paulataigy@gmail.com.
} 


\section{Introdução}

A família e a escola são as duas principais instituições de formação do ser humano e, como toda relação de poder, há entre elas expectativas recíprocas, especialmente no que se refere à competência e à divisão do trabalho em relação à educação da criança. Nesse contexto, reconhece-se a diversidade de organizações familiares existentes na atualidade e toma-se como referência de "família" toda unidade ou configuração composta por, pelo menos, um adulto e uma criança ou adolescente (OLIVEIRA; MARINHO-ARAÚJO, 2010).

Partindo dessa concepção, compreende-se a relação família-escola, segundo Silva (2010), como sendo constituída por duas vertentes (escola e lar) e por duas dimensões de atuação (individual e coletiva). A primeira vertente, denominada "escola", é a mais visível e implica toda atividade realizada pelos pais/responsáveis na instituição de ensino, por exemplo, conversas ou encontros com a direção ou corpo docente, participações em reuniões, eventos, órgão de gestão etc. A segunda (lar), menos visível, engloba as ações desempenhadas em casa, com a participação familiar e do estudante, e se refere ao acompanhamento e auxílio nas atividades escolares, deveres de casa, leituras, revisão do conteúdo, ou seja, as ações fomentadas por algum membro da família, fora da escola, que promovem o apoio e o incentivo da aprendizagem do educando.

Quanto às dimensões de atuação, a relação família-escola, quando acontece numa dimensão individual, diz respeito a qualquer ação que o familiar toma em relação à educação e no interesse do educando. Quando se dá numa dimensão coletiva, envolve práticas em defesa de interesses difusos, por exemplo, quando o responsável atua em nome ou na esfera de uma associação de representantes parentais, em órgãos colegiados na escola, no governo etc.

O presente trabalho, portanto, é fruto de reflexões resultantes de um projeto de extensão universitária, realizado em 2017, pelo Campus IV (Litoral Norte) da UFPB, denominado "Família, escola e desenvolvimento de aprendizagem", que tinha como fim estimular a participação familiar no acompanhamento da aprendizagem da criança, no caso específico, jovens matriculados no II ciclo do ensino fundamental de duas escolas da rede pública de ensino do município de Mamanguape/PB.

Apesar de as ações terem ocorrido em duas escolas públicas da Zona da Mata paraibana, o cenário social encontrado se repete em contextos semelhantes em qualquer região do Brasil. Destarte, partindo dessa experiência local, percebeu-se a dificuldade existente no âmago desta relação (família-escola) em escolas públicas com famílias de baixa renda.

As universidades públicas são ancoradas no princípio da indissociabilidade entre ensino, pesquisa e extensão - artigo 207 da Constituição Federal (BRASIL, 1988) e artigo 43 da Lei de Diretrizes e Bases da Educação (BRASIL, 1996). As ações de extensão têm por finalidade, dentre outras, "estimular o conhecimento dos problemas do mundo presente, em particular os nacionais e regionais, prestar serviços especializados à comunidade e estabelecer com esta 
uma relação de reciprocidade" - artigo 43, da lei no 9.394/1996 (BRASIL, 1996). Portanto, desta experiência acadêmica, que proporcionou um contato com as instituições de ensino da rede pública do município de Mamanguape e os familiares de alunos de baixa renda, surgiu a seguinte inquietação: É possível aprimorar a relação "família-escola" e construir um diálogo construtivo entre essas duas esferas?

O Brasil é um dos países participantes do PISA (Programa Internacional de Avaliação de Estudantes), coordenado pela OCDE (Organização para Cooperação e Desenvolvimento Econômico) e, segundo o relatório de 2015, o desempenho dos estudantes brasileiros na prova, que avalia três áreas de conhecimento (Leitura e Língua Portuguesa; Matemática e Ciência, além de Competências Financeira e de Resolução Colaborativa de Problemas) está abaixo da média geral dos países integrantes da OCDE.

De acordo com o estudo desenvolvido pelo Centro de Políticas Públicas do Insper e da USP (SASSAKI. et al., 2018), esse baixo desempenho pode ter como causa não apenas a falta de domínio e falhas no aprendizado do conteúdo, mas, também, a ausência de habilidades socioemocionais, como, por exemplo, perseverança, motivação, confiança e resiliência. Nesse aspecto, a educação primária (familiar) é de vital importância para a construção da base emocional do educando. O que demonstra, mais uma vez, a importância dessa relação família -escola, principalmente como objeto de estudo para pesquisas acadêmicas.

Destarte, o presente trabalho foi desenvolvido como fruto de uma experiência de extensão universitária, com o intuito de apresentar algumas reflexões sobre o respectivo tema. Para tanto, utilizou-se o método bibliográfico, bem como o relato de experiência, para abordar a relação família-escola em um contexto com pessoas de baixa renda.

\section{Metodologia}

O presente trabalho foi desenvolvido em três etapas. A primeira se refere à apresentação do estudo de caso - o projeto de extensão universitária "Família, escola e desenvolvimento de aprendizagem" -, que motivou as reflexões e questionamentos que resultaram nesta pesquisa.

No segundo momento, realizou-se a apuração e análise de alguns dados socioeconômicos da região, coletados a partir de fontes secundárias, os quais serviram como pano de fundo para a contextualização acerca da realidade social e educacional das famílias participantes do projeto, a fim de auxiliar na compreensão do contexto social e da realidade local e como isso pode interferir na relação das famílias com a escola.

Por fim, uma vez realizada a observação crítica da realidade local, partiu-se para uma análise macro da situação, com o objetivo de compreender a natureza das instituições, baseadas na perspectiva de autores clássicos como: Pierre Bourdieu e Passeron (1992), Saviani (1997), Pedro Silva (2010), entre outros autores contemporâneos, para entender o que está por trás dessa relação (função social e natureza simbólica existente). Por último, pontuou-se algumas 
sugestões para a construção de um diálogo possível, baseado especialmente em uma experiência bem-sucedida, realizada pela Secretaria de Educação do Município de Lagoa de Dentro/PB.

No campo científico, Richardson e colaboradores (1999, p. 70) definem o método como “a escolha de procedimentos sistemáticos para a descrição e explicação de fenômenos". Esses procedimentos podem configurar as chamadas abordagens quantitativas ou qualitativas, muito embora autores como Goode e Hatt (1973, p. 398), por exemplo, discordem dessa dicotomia e cheguem a afirmar que: "A pesquisa moderna deve rejeitar como uma falsa dicotomia a separação entre estudos 'qualitativos' e 'quantitativos', ou entre ponto de vista 'estatístico' e não 'estatístico'. Além disso, não importa quão precisas sejam as medidas, o que é medido continua a ser qualidade."

Neste trabalho, optou-se pelo método qualitativo diante de uma perspectiva iniciada a partir de um caso específico (projeto de extensão universitário "Família, escola e desenvolvimento de aprendizagem"). Para Yin (2005, p. 19), o Estudo de Caso torna-se particularmente adequado "quando o pesquisador tem pouco controle sobre os acontecimentos e quando o foco se encontra em fenômenos contemporâneos inseridos em algum contexto da vida real".

O projeto de extensão universitária, ora relatado, foi realizado durante os anos de 2017/2018, correspondentes aos períodos acadêmicos 2017.2/2018.1, no Campus IV (Litoral Norte), da UFPB, denominado "Família, escola e desenvolvimento de aprendizagem", que tinha como fim estimular a participação familiar no acompanhamento da aprendizagem da criança, no caso específico, jovens matriculados no II ciclo do ensino fundamental de duas escolas da rede pública de ensino do município de Mamanguape/PB.

A ação do projeto consistia em realizar oficinas pedagógicas para os pais/responsáveis dos alunos matriculados no II ciclo de ensino fundamental (público-alvo) de duas escolas da rede pública de ensino do município de Mamanguape: a Escola Estadual de Ensino Fundamental e Médio (EEEFM) Umbelina Garcez e a Escola Municipal de Ensino Fundamental (EMEF) Prof. Adailton Coelho Costa, para discutir e refletir o papel de cada instituição (família e escola), no intuito de despertar neles a relevância do acompanhamento familiar em relação à aprendizagem do educando. A escolha dessa faixa etária se justifica pelo fato de que experiências demonstram que é a partir desta fase que se observa um afastamento gradativo das famílias quanto ao acompanhamento da vida escolar de seus filhos(as)/tutelados(as).

O projeto consistia na realização de oficinas pedagógicas desenvolvidas com o intuito de tratar da relevância do acompanhamento familiar para o desempenho escolar do educando e da participação da família no ambiente escolar. Além das oficinas pedagógicas, desenvolveu-se uma cartilha educativa com informações jurídicas sobre o direito à educação dos menores, bem como dicas e sugestões de atividades para serem executadas no seio familiar e que funcionariam como estímulos positivos para o desenvolvimento e aprendizagem do estudante. Em um segundo plano, as ações visaram também sensibilizar a comunidade escolar e promover uma 
maior participação das famílias dos estudantes na vivência/gestão escolar, bem como avaliar o trabalho de incentivo à participação familiar nas instituições visitadas.

Por ser a sede da região metropolitana denominada Vale do Mamanguape, as escolas estaduais da rede pública de ensino de Mamanguape costumam receber alunos advindos das diversas prefeituras da região, especialmente aqueles que residem em zonas rurais. Esse é, por exemplo, o cenário vivenciado na EEEFM Umbelina Garcez, onde se realizaram as primeiras oficinas pedagógicas. Ao todo, a escola possuía, à época do projeto, 187 alunos matriculados no II ciclo do Ensino Fundamental no turno da manhã e 155 matriculados no turno da tarde; de forma que se optou por realizar duas oficinas, uma para cada turno.

Já a EMEF Prof. Adailton Coelho Costa está localizada em uma zona mais periférica do município de Mamanguape, cujas famílias vivem em condições desfavoráveis e com baixa renda per capita. Ao todo, segundo informações da diretoria da escola, são apenas quatro turmas (uma para cada ano do II ciclo do ensino fundamental: $6^{\circ}, 7^{\circ}, 8^{\circ}$ e $9^{\circ}$ ), todas no horário vespertino, com uma média de quinze a vinte alunos cada, todas bastante heterogêneas (diversas faixas etárias numa mesma classe e com alunos repetentes).

Foram impressas cartas-convites (já que a forma escrita era o meio de comunicação adotado, segundo as escolas, de interlocução com os pais/responsáveis e de divulgação de avisos), que continham informações sobre o tema a ser abordado, tais como data, hora e local, chamando-os para participarem de um lanche coletivo ao final das oficinas. As entregas foram feitas pelas monitoras do projeto que visitaram as escolas citadas em ocasiões (dias/horários) distintos: na primeira instituição (EEEFM Umbelina Garcez), em seis oportunidades (três vezes em cada turno: manhã e tarde) e, na segunda (EMEF Prof. Adailton Coelho), em três momentos distintos, durante o turno escolar (vespertino). Durante as visitas, as monitoras (discente bolsista e a voluntária do projeto) entravam nas classes e se comunicavam diretamente com os alunos, explicando o projeto, a importância da presença dos pais/responsáveis, apresentavam o conteúdo a ser abordado nas oficinas e finalizavam com a entrega dos convites.

Entretanto percebeu-se que os estudantes tinham receio da presença dos pais/responsáveis na escola, afirmavam que não iriam chamá-los, pois tinham medo que eles fossem informados sobre seus comportamentos ou sobre seus rendimentos escolares. Foi preciso reforçar que as oficinas pedagógicas não tinham esse objetivo. Destarte, detectou-se, neste momento, um dos primeiros problemas da relação entre as instituições e os familiares: os pais/responsáveis só eram convidados para irem até a escola quando da entrega dos boletins dos alunos ou da presença de algum problema de relacionamento/comportamento com o menor. Segundo depoimentos colhidos repetidamente nas oficinas, os responsáveis eram chamados apenas para "ouvirem reclamação" sobre os seus filhos(as)/tutelados(as).

Apesar do empenho da equipe na divulgação e preparo das oficinas/cartilhas, a adesão às mesmas foi significativamente baixa em ambas as escolas. Menos de $3 \%$ dos representantes estiveram presentes, conforme registro de assinaturas em lista de presença, no dia da realização 
da oficina. Ao fim do projeto, percebeu-se o baixíssimo nível de envolvimento real entre as duas esferas em ambas as escolas. As instituições promovem poucas (ou quase nenhumas) ações no sentido de se reverter o quadro.

Por outro lado, constatou-se que existe um anseio dos pais/responsáveis por mais informações sobre a vida/gestão escolar de seus filhos(as)/tutelados(as), entretanto, há também uma resistência deles no sentido de se integrar à comunidade escolar (talvez, ou principalmente pela barreira, dificuldade e/ou pouca receptividade que encontram). Julgam, muitas vezes, como se não pertencessem àquele ambiente ou como se os problemas ali existentes (inclusive em relação à aprendizagem/comportamento dos menores) não fossem de suas responsabilidades, mas sim, da escola (um campo autônomo e independente).

É certo que esse resultado (em relação à baixa adesão por parte dos pais/responsáveis) pode ter se dado por inúmeros fatores, contudo, é preciso observar essa relação em sua natureza, para enxergar o viés do problema que se põe, que é o distanciamento e a pouca participação da família na vida escolar e no processo de aprendizagem do educando de baixa renda. Os desafios e as dificuldades que surgem dessa relação produzem distorções importantes à formação, com prejuízos para as práticas de inclusão das famílias nas escolas. É preciso refletir, portanto, sobre projetos para melhorar a convivência e a relação dessas duas entidades (família e escola).

\section{A realidade social das famílias e dos estudantes das escolas públicas em Mamanguape}

O Nordeste brasileiro se destaca como a região que apresenta os maiores índices de analfabetismo, segundo aponta a Pesquisa Nacional por Amostra de Domicílios Contínua (Pnad Contínua) da Educação 2018 (IBGE, 2019). Em comparação com os demais estados nordestinos, a Paraíba se coloca na quarta posição, registrando a taxa de $16,1 \%$ da sua população com quinze anos ou mais analfabeta, atrás apenas dos estados de Alagoas, Piauí e Maranhão (IBGE, 2019). Enquanto o índice nacional, nesse quesito, é de apenas 6,8\%. Regiões como Sul e Sudeste, por exemplo, apresentam os melhores índices do país com somente 3,5\% (IBGE, 2019).

A cidade de Mamanguape fica a cerca de sessenta quilômetros da capital paraibana (João Pessoa) e é sede da Região Metropolitana do Vale do Mamanguape, composta por outros oito municípios, todos caracterizados pelos baixos índices socioeconômicos e educacionais e pela exploração da cana-de-açúcar e do trabalho nas usinas sucroalcooleiras. De acordo com dados do IBGE (2017a), em 2017, o PIB per capita de Mamanguape era R\$13.890,28 e o salário médio mensal na região era de 1.8 salários mínimos (IBGE, 2017b). Quanto à proporção de pessoas ocupadas em relação à população total, era de apenas 16.3\% (IBGE, 2017b).

Em relação ao desempenho da educação, com base nos resultados do Saeb (Sistema de Avaliação da Educação Básica), cujo principal objetivo é mensurar a qualidade do ensino ministrado nas escolas das redes públicas e é realizado a cada dois anos, o município de Mamanguape apresentou índices abaixo da média do Estado da Paraíba. Em 2015 e 2017, os 
índices gerais nos anos iniciais ( $5^{\circ}$ ano) e finais ( $9^{\circ}$ ano) do ensino fundamental, entre as escolas públicas (federal, estadual e municipal) foram (INEP, 2015a, 2017a):

IDEB Ensino Fundamental - anos iniciais e finais:

\begin{tabular}{|c|c|c|c|c|c|c|c|c|c|}
\hline & & \multicolumn{4}{|c|}{$\begin{array}{c}\text { Paraíba } \\
\text { (Îndice geral): }\end{array}$} & \multicolumn{4}{|c|}{$\begin{array}{l}\text { Mamanguape } \\
\text { (Îndice geral): }\end{array}$} \\
\hline & & $\begin{array}{l}\text { Resultado } \\
\text { (2015): }\end{array}$ & $\begin{array}{l}\text { Meta } \\
\text { (2015): }\end{array}$ & $\begin{array}{l}\text { Resultado } \\
\text { (2017): }\end{array}$ & $\begin{array}{l}\text { Meta } \\
(2017):\end{array}$ & $\begin{array}{l}\text { Resultado } \\
\text { (2015): }\end{array}$ & $\begin{array}{c}\text { Meta } \\
\text { (2015): }\end{array}$ & $\begin{array}{l}\text { Resultado } \\
\text { (2017): }\end{array}$ & $\begin{array}{c}\text { Meta } \\
(2017):\end{array}$ \\
\hline a) & $5^{\circ}$ ano: & 4.5 & 4.1 & 4.7 & 4.4 & 3.8 & 3.9 & 3.5 & 4.2 \\
\hline b) & 9o ano: & 3.5 & 3.7 & 3.6 & 4.0 & 3.2 & 3.6 & 2.7 & 3.9 \\
\hline
\end{tabular}

Fonte: Elaboração própria, com base nos resultados do IDEB 2015/2017 (INEP, 2015a, 2017a)

Pode-se perceber que no município de Mamanguape, em 2017, nenhuma das duas metas do ensino fundamental (inicial/final) foram atingidas no IDEB. Pior, os índices foram menores do que os observados em 2015, indicando que, provavelmente, não houve ganhos de aprendizagem relevante durante esse período, nessa fase educacional.

Em relação ao FUNDEB, o percentual de distribuição da receita de Mamanguape, em comparação ao orçamento estimado da Paraíba, percebe-se que ele sofreu uma queda no ano de 2017, contudo, está em processo de recuperação nos últimos dois anos, consoante os dados apresentados na tabela demonstrativa (MEC/FNDE, 2015a/2015b, 2016a/2016b, 2017a/2017b, 2018a/2018b, 2019a/2019b):

Estimativa de receitas do FUNDEB:

\begin{tabular}{lrrr}
\hline Ano (exercício): & Paraíba: & Mamanguape: & $\begin{array}{r}\text { *Percentual de } \\
\text { distribuição } \\
\text { (em relação à PB): }\end{array}$ \\
$\mathbf{2 0 1 5}$ & $\mathrm{R} \$ 2.394 .309 .423,50$ & $\mathrm{R} \$ 17.463 .887,59$ & $0,72 \%$ \\
$\mathbf{2 0 1 6}$ & $\mathrm{R} \$ 2.427 .264 .604,35$ & $\mathrm{R} \$ 18.224 .224,25$ & $0,75 \%$ \\
$\mathbf{2 0 1 7}$ & $\mathrm{R} \$ 2.509 .881 .011,21$ & $\mathrm{R} \$ 16.288 .055,53$ & $0,64 \%$ \\
$\mathbf{2 0 1 8}$ & $\mathrm{R} \$ 2.662 .171 .002,04$ & $\mathrm{R} \$ 17.947 .389,72$ & $0,67 \%$ \\
$\mathbf{2 0 1 9}$ & $\mathrm{R} \$ 2.805 .504 .303,821$ & $\mathrm{R} \$ 19.359 .878,23$ & $0,69 \%$ \\
\hline
\end{tabular}

FONTE: Elaboração própria, com base no valor anual por aluno estimado, no âmbito do Distrito Federal e dos Estados dos Estados, e a estimativa de receita do Fundeb, em relação ao $\mathrm{n}^{\circ}$ de matrículas, coeficientes de distribuição de recursos e receita anual prevista por Estado e Município (MEC/FUNDEB, 2015a/2015b, 2016a/2016b, 2017a/2017b, 2018a/2018b, 2019a/2019b) 
Se pegarmos o montante (cota-parte) da transferência de recursos (receita) do FUNDEB para Mamanguape e dividir pelo número de matrículas na rede pública de ensino (estadual e municipal), em escolas urbanas e rurais, teremos um valor anual por aluno estimado, daquele ente federativo. Destarte, o quadro a seguir faz uma comparação com esse valor municipal estimado, o valor anual por aluno estimado no estado da Paraíba, e o definido anualmente, pelo Poder Executivo federal, nos termos do artigo 15, inciso IV, da Lei ${ }^{\circ} 11.494$, de 20 de junho de 2007.

\begin{tabular}{lcccrc}
\hline \multicolumn{5}{c}{ Valor anual estimado por aluno (Receitas do FUNDEB): } \\
\hline $\begin{array}{l}\text { Ano } \\
\text { (exercício) }\end{array}$ & Nacional $^{1}:$ & Paraíba $^{2}:$ & Mamanguape: & $\begin{array}{r}\text { No de matrículas na } \\
\text { Educação Básica, } \\
\text { na rede pública de } \\
\text { Mamanguape: }\end{array}$ & $\begin{array}{r}\text { No de matrículas no } \\
\text { Ens. Fundamental, } \\
\text { na rede pública de } \\
\text { Mamanguape: }\end{array}$ \\
\hline $\mathbf{2 0 1 5}$ & $\mathrm{R} \$ 2.890,42$ & $\mathrm{R} \$ 2.285,57$ & $\mathrm{R} \$ 1.750,77$ & 9.975 & 6.056 \\
$\mathbf{2 0 1 6}$ & $\mathrm{R} \$ 2.739,87$ & $\mathrm{R} \$ 2.545,31$ & $\mathrm{R} \$ 1.875,50$ & 9.717 & 5.860 \\
$\mathbf{2 0 1 7}$ & $\mathrm{R} \$ 2.875,03$ & $\mathrm{R} \$ 2.739,77$ & $\mathrm{R} \$ 1.666,13$ & 9.776 & 5.976 \\
$\mathbf{2 0 1 8}$ & $\mathrm{R} \$ 3.016,67$ & $\mathrm{R} \$ 2.926,56$ & $\mathrm{R} \$ 1.884,64$ & 9.523 & 5.671 \\
$\mathbf{2 0 1 9}$ & $\mathrm{R} \$ 3.238,52$ & $\mathrm{R} \$ 3.048,73$ & $\mathrm{R} \$ 2.043,26$ & 9.475 & 5.633 \\
\hline
\end{tabular}

FONTE: Elaboração própria, com base nos dados Brasil (2007), MEC/FNDE (2015a, 2016a, 2017a, 2018a, 2019a) e INEP (2014, 2015b, 2016, 2017b, 2018a).

Como se pode perceber, o ano de 2017 apresentou o menor valor anual estimado por aluno, provavelmente, se for confirmado ${ }^{3}$, se deu em razão da redução do percentual de distribuição das receitas do FUNDEB para aquele município, no período em questão.

Quando observamos os resultados do Brasil no PISA, o status socioeconômico é um forte prenunciador de desempenho das habilidades medidas (leitura, matemática e ciências). Segundo os dados divulgados pela Organização para Cooperação e Desenvolvimento Econômico OCDE (2019), os alunos das classes mais favorecidas superaram, em 97 pontos, os resultados

1 Conforme o $\$ 1^{\circ}$, do art. $4^{\circ}$, da Lei $\mathrm{n}^{\circ} 11.494 / 2007$, o valor anual mínimo por aluno, definido nacionalmente, constitui-se valor de referência, relativo aos anos iniciais do ensino fundamental urbano, e será determinado contabilmente em função da complementação da União (BRASIL, 2007).

2 Valor anual por aluno estimado, no âmbito do estado da Paraíba, relativo aos anos (séries) iniciais do ensino fundamental urbano, com base nos dados divulgados anualmente, pelas Portarias Interministerial do Poder Executivo Federal (MEC/FNDE - 2015a, 2016a, 2017a, 2018a, 2019a).

3 Solicitou-se formalmente, através de e-mail, com base na lei de acesso à informação (Lei $n^{\circ}$ 12.527/2011), à Secretaria de Educação e Cultura de Mamanguape, a confirmação do valor anual gasto por aluno, no período mencionado, porém não obtivemos resposta. 
dos estudantes das classes mais baixas. De acordo com os dados socioeconômicos colhidos na aplicação do exame de 2015 (de forma amostral), entre os alunos matriculados a partir do $7^{\circ}$ ano do ensino fundamental, $43 \%$ dos alunos se situam entre os $20 \%$ mais desfavorecidos na escala internacional de níveis socioeconômicos do PISA, enquanto a média dos países integrantes da OCDE é de apenas $12 \%$. Não obstante, cerca de $10 \%$ desses estudantes, classificados nessa faixa econômica, em 2018, conseguiram atingir o mesmo quadrante de desempenho, em leitura, dos alunos mais favorecidos, demonstrando que, felizmente, a desvantagem não é um destino.

Em relação à escolaridade dos pais/responsáveis desses jovens, de acordo com a OCDE (2016), menos de 15\% dos adultos na faixa etária de 35 a 44 anos de idade possuem o ensino superior completo. Essa média é confirmada pelo Inep (2018b, p. 154), no Relatório do $2^{\circ}$ Ciclo de Monitoramento das Metas do Plano Nacional da Educação - 2018, em que demonstra que a escolaridade média brasileira (em anos de estudo) da população de 18 a 29 anos de idade era, em 2016, de 10,2 anos. Entretanto, nas regiões Norte e Nordeste do país, a escolaridade média desse grupo baixa para 9,4 anos (2018b, p. 154).

Quando se refere à escolaridade média, em anos de estudo, dessa população (18 a 29 anos de idade) pertencente aos $25 \%$ mais pobres (com base na renda domiciliar per capita) no Brasil, esse índice cai para 8,4 anos. Quando se compara, contudo, a escolaridade desse grupo (vulneráveis) com a dos jovens e adultos pertencentes às classes de maior renda, a escolaridade média, em 2016, salta para 12,2 anos. Esse é um dado tão preocupante que se transformou em um objetivo do Plano Nacional de Educação, inserido na Meta 8, isto é, o compromisso de elevar a escolaridade média da população de 18 (dezoito) a 29 (vinte e nove) anos:

\footnotetext{
De modo a alcançar, no mínimo, 12 (doze) anos de estudo no último ano de vigência deste plano, para as populações do campo, da região de menor escolaridade no país e dos $25 \%$ (vinte e cinco por cento) mais pobres, e igualar a escolaridade média entre negros e não negros declarados à fundação Instituto Brasileiro de Geografia e Estatística - IBGE" (INEP, 2018b p. 151).
}

Ainda com base no relatório de desempenho do Brasil no PISA 2018, elaborado pela OCDE (2019), quando perguntados sobre a continuidade de estudo em nível superior, cerca de 1 em cada 10 estudantes, com bom desempenho escolar, mas pertencentes às classes mais desfavorecidas, não possui expectativa de completar o ensino superior, enquanto essa relação é de 1 em cada 25 estudantes entre os que pertencem às classes mais favorecidas. Não se tem, contudo, informações quanto às percepções e envolvimento dos pais na escola e no aprendizado de seus filhos. Porém, no geral, os estudantes cujas famílias valorizam a educação como fator de ascensão econômica, desfrutam de um melhor clima familiar e recebem maior apoio dos pais, possuem mais chances de concluir os estudos e têm menos chance de abandonar a escola (OCDE, 2019). 


\section{Fundamentação teórica}

A fundamentação teórica foi desenvolvida a partir da realização de uma pesquisa bibliográfica sobre o tema, que Martins e Lintz (2002, p. 29) definem como a pesquisa "baseada em referências teóricas publicadas em livros, revistas ou periódicos", no intuito de compreender se é possível a construção de um diálogo entre essas duas esferas (família e escola). A seguir, algumas conclusões sobre este tema, que puderam ser formuladas a partir da experiência da extensão universitária relatada, assim como em decorrência da doutrina consultada/pesquisada.

Família - escola: o que está por trás dessa relação?

Durante a preparação das oficinas pedagógicas e das cartilhas, o principal objetivo foi delimitar qual a função social dessas duas instituições, já que a ambas competem a função e o dever de educar a criança, segundo o artigo 207 da Constituição Federal (BRASIL, 1988) e o artigo 43 da Lei de Diretrizes e Bases da Educação (BRASIL, 1996). Apesar desse ponto comum que lhes une, não há, porém, entre elas, uma relação de dependência, mas sim, um conjunto de expectativas recíprocas.

Existem entre essas duas instituições (família e escola), portanto, responsabilidades e funções que foram mudando ao longo da história. A educação familiar, primeiramente, é mais antiga do que a escolar. Segundo diversos autores (SILVA, 2010; OLIVEIRA; MARINHOARAÚJO, 2010), aquela assumiu diferentes formas ao longo do tempo e tem como principal função a transmissão de valores morais e costumes, conforme a época histórica e o tipo de sociedade na qual está inserida.

A essa educação, no sentido de transmitir papéis sociais, é tradicionalmente chamada de educação primária, uma vez que tem como "tarefa principal orientar o desenvolvimento e aquisição de comportamentos considerados adequados, em termos dos padrões sociais vigentes em determinada cultura" (OLIVEIRA; MARINHO-ARAÚJO, 2010, p. 101).

A segunda nasce junto com o processo formal de educação, que inclui, entre outros aspectos, a promoção do acesso à leitura e à escrita (SILVA, 2010). Tem como principal função a transmissão do saber letrado, da produção de conhecimento desenvolvida ao longo do tempo e exerce (historicamente) a função de legitimar a ordem social.

Para Saviani (1997), as teorias educacionais são divididas em dois grupos: as que entendem educação como instrumento de equalização social e, logo, de superação da marginalidade, ou as que compreendem educação como instrumento de discriminação social, portanto, um fator de marginalização. Silva (2010, p. 444) é categórico ao afirmar que "dois traços caracterizarão durante muito tempo a 'escola': a) será, até recentemente, para uma minoria; e b) exige a separação de funções entre as famílias e alguém especializado no 'saber escolar"'. 
Ao longo da história, o acesso à educação formal sempre foi restrito à elite. Não obstante, na Europa Central, nos Séculos XVI e XVII, como consequência da Reforma Protestante, os teóricos reformadores já defendiam o letramento universal para que todos os cristãos pudessem ler suas bíblias e interpretá-las, o que exigia a criação de escolas e a universalização do ensino (COMENIUS 4 , 1649 apud SILVA, 2010, p. 445). No entanto a consolidação do direito a uma escolaridade obrigatória e gratuita só veio a se firmar mesmo no século XIX.

Destarte, o processo de escolarização de massas do ensino primário somente se estabeleceu quando passou a ser interesse da burguesia educar os filhos do proletariado, para consolidar a ordem democrática vigente (SAVIANI, 1997), o que permitiu o acesso à escola por parte de uma maioria não letrada da população. A partir de então, consubstanciou-se a especialização de funções entre pais e professores e, inevitavelmente, entre a família e a instituição escolar, que passou a se posicionar em um lugar de superioridade em face das famílias (SILVA, 2010).

Apesar de a institucionalização da educação formal, até então restrita à elite, ter sido viabilizada com o apoio da burguesia, surgem, a partir de então, os conflitos de interesses (classes), os quais estavam submersos sob o objetivo em comum (SAVIANI, 2010). O acesso à educação pela classe dominada provoca sua organização e faz surgir os movimentos sociais que conclamam a população para reivindicar seus direitos, especialmente em defesa da criação de escolas públicas para os trabalhadores.

A partir desse ponto, volta-se a ruptura, pois não mais interessa à burguesia que o povo se aproprie do conhecimento. A consequência é o surgimento de teorias pedagógicas que beneficiam e aprimoram o ensino destinado às elites e facilitam o "rebaixamento do nível do ensino destinado às camadas populares" (SAVIANI, 2010, p. 58). Assim, a educação passa, mais uma vez, a ser um instrumento que reforça a marginalização e que legitima a ordem social.

Seguindo este entendimento, Bourdieu e Passeron (1992, p. 22) apontam o sistema de ensino como um instrumento de legitimação da cultura dominante que provoca uma violência simbólica, uma segregação que favorece aqueles que se encontram mais próximos do capital cultural vigente, ou seja, um sistema que provoca a seleção e a legitimação dessa marginalidade:

A força simbólica de uma instância pedagógica define-se por seu peso na estrutura das relações de força e das relações simbólicas (exprimindo sempre essas relações de força) que se instauram entre as instâncias exercendo uma ação de violência simbólica, estrutura que exprime por sua vez as relações de força entre os grupos ou classes constitutivas da formação social considerada.

4 Comenius, conhecido como o pai da didática moderna, defendeu a universalidade da educação em sua obra "Didática Magna”, também conhecida por “Tratado da Arte Universal de Ensinar Tudo a Todos”, publicado em 1649. (Quem foi Comenius? Editora Comenius. [documento eletrônico] Disponível em: <http://editoracomenius. com.br/index.php?id_cms=6\&controller=cms $>$. Acesso em: 29 jul. 2018). 
E continuam os autores:

Numa formação social determinada, a Ação Pedagógica (AP) que as relações de força entre os grupos ou classes constitutivas dessa formação social põem em posição dominante no sistema das Ações Pedagógicas é aquela que, tanto por seu modo de imposição como pela delimitação daquilo que ela impõe e daqueles a quem ela impõe, corresponde (...) aos interesses objetivos (materiais, simbólicos e, sob a relação considerada aqui, pedagógicos) dos grupos ou classes dominantes (BOURDIEU; PASSERON, 1992, p. 22).

Ou seja, o sistema de ensino (escola) reproduz as relações de força entre as classes sociais, consequentemente, esse conflito também se repete na relação família-escola, uma vez que essa se apresenta em uma posição de superioridade em face daquela (família). E quanto maior a distância do capital cultural dominado pela família do educando em relação ao arbitrário cultural reproduzido pela ação pedagógica (escola), maior se converte a posição de superioridade da instituição em relação à família.

Os alunos que não se enquadram no suposto modelo desejado pela escola tornam-se responsabilidade da família, isto é, o sistema isenta-se de culpa pela não assimilação do arbitrário cultural e pela dificuldade de aprendizagem do estudante e culpam a família pelo problema. Surgem, então, as expectativas da escola em relação à divisão do trabalho de educar com as famílias (principalmente no que tange ao comportamento dos estudantes), porém, essa abertura de diálogo e divisão de responsabilidades é limitada aos interesses da escola.

Segundo Oliveira e Marinho-Araújo (2002, p. 102), a ideia de que a família é a base da criança, "o locus afetivo e condição sine qua non de seu desenvolvimento", pode posicionar, mais uma vez, "a família no lugar de desqualificada", quando esse desempenho não é bom. Conforme explanam os autores que "nesse enfoque, as razões de ordem emocional e afetiva ganham um colorido permanente quanto ao entendimento da relação família-escola e da ocorrência do fracasso escolar. Ganha status natural a crença de que uma 'boa' dinâmica familiar é responsável pelo 'bom' desempenho do aluno” (OLIVEIRA; MARINHO-ARAÚJO, 2002, p.102).

Destarte, este enfoque psicológico dado à relação família x escola considera o contexto psicológico do aluno um dos grandes responsáveis pelo baixo rendimento dele e acaba gerando um processo de culpabilização e não de responsabilização compartilhada (OLIVEIRA; MARINHO-ARAÚJO, 2010).

Por outro lado, estudos demonstram a correlação entre habilidades cognitivas e socioemocionais e o desenvolvimento do estudante. Recentemente, uma pesquisa elaborada pelo Centro de Políticas Públicas do Insper demonstrou que as diferenças nas quedas de desempenho dos estudantes ao longo de uma prova, especialmente exames que medem resultados com base em respostas objetivas, como o PISA, "refletem habilidades socioemocionais, tais como persistência, concentração e determinação" (SASSAKI et al., 2018, p. 2) da população dos países. De acordo com os autores, este impacto supera, inclusive, "indicadores construídos a partir de 

em escolas da rede pública do município de Mamanguape/PB

informações auto relatadas, que limita a comparabilidade entre indivíduos e regiões" (SASSAKI, et al., 2018, p. 02).

Sabe-se, portanto, que a família fomenta o processo de socialização, de proteção, na medida em que (idealmente) deve oferecer as condições de desenvolvimento social, cognitivo e afetivo a todos os seus membros. Entretanto, ao longo das últimas décadas, essa instituição vem sofrendo inúmeras transformações sociais, as quais vêm afetando sua relação com a escola e desconfigurando papéis sociais historicamente atribuídos.

Essas transformações sociais são dinâmicas e suas consequências, tanto de ordem interna quanto externa, ainda são assimiladas no cotidiano. O direito ao divórcio, a conquista do mercado de trabalho e a luta das mulheres pela igualdade de gênero, os novos arranjos familiares (famílias socioafetivas, monoparental, anaparental etc.), os direitos LGBTQ+ e as uniões homoafetivas, a luta por políticas inclusivas, o engajamento da sociedade civil organizada, as inovações e ferramentas tecnológicas que alteraram a dinâmica de comunicação das escolas com as famílias (como, por exemplo, o uso de aplicativos de comunicação como whatasapp, redes socais, entre outros) têm provocado alterações na relação família-escola.

Pode-se dizer que é um processo contínuo de mudanças de um padrão antes estabelecido para um cenário ainda em transformação. Em contrapartida, tem-se a instituição escolar, cuja estrutura se mantém praticamente inalterada, e que tem enfrentado dificuldades para acompanhar e para se adaptar a essas mudanças sociais e tecnológicas contemporâneas, especialmente as escolas públicas em comunidades de baixa renda, as quais, muitas vezes, insistem em reforçar esse modelo de hierarquia e de distanciamento das famílias.

Pedro Silva (2010) aponta dois movimentos importantes decorrentes de todo esse processo de transformação e que influenciam diretamente a relação família $\mathrm{x}$ escola, mas no sentido ao da culpabilização das famílias, compreendendo que a escola passou a assumir funções/papeis sociais que antes não lhe cabiam:

\footnotetext{
Por um lado, nas famílias, temos cada vez mais ambos os membros do casal a trabalhar, o que provoca a entrada cada vez mais precoce das crianças para a instituição escolar ou para-escolar ${ }^{5}$ (creche, amas, jardim de infância, etc.). Isto tem como consequência uma alteração das relações tradicionais entre socialização primária e secundária, conduzindo a "uma espécie de secundarização da socialização primária e de primarização da socialização secundária” e àquilo que designo por um processo de parentização docente; por outro, a crescente dificuldade da escola em assumir sozinha a plenitude do seu projecto educativo (SILVA, 2010, p. 446, grifo nosso).
}

Portanto, Silva (2010) descreve acima dois fenômenos da atualidade importantes que influenciam na relação família x escola. O primeiro é o que ele chama de "parentização docente".

$5 \mathrm{O}$ que equivale no Brasil à educação infantil, que engloba creches ou entidades equivalentes (para crianças de até três anos de idade) e pré-escolas, para crianças de 4 (quatro) a 5 (cinco) anos de idade, conforme artigo 30 da LDB (BRASIL, 1996). 
Esse é um fenômeno contemporâneo, em que, com a ida da mulher ao mercado de trabalho, ou, no caso dos novos desenhos familiares, com a necessidade do(s) membro(s) familiar(es) trabalharem por questões financeiras, há cada vez mais a urgência de matricularem seus filhos/ tutelados precocemente no sistema escolar, o que tem provocado duas consequências imediatas: a primeira é de ordem jurídica, que é a necessidade de o Estado ofertar instituições que atendam a essa demanda. A segunda é de ordem social, que é a alteração das relações tradicionais de socialização primária da criança, que antes ficava a cargo exclusivo das famílias, mas que agora, com a ida às creches em idade tenra, passou a ficar a cargo também das escolas, ocasionando uma espécie de "parentização docente" (SILVA, 2010, p. 446).

Assim, se de um lado essa relação/contato com a família do menor tem se iniciado cada vez mais cedo, já na educação infantil, com a ida do bebê às creches públicas, por exemplo; a medida que a criança vai crescendo e se desenvolvendo dentro do sistema educacional, a experiência demonstra que a relação da escola com a família vai se distanciando, e aumentando, consequentemente, a dificuldade da escola em assumir sozinha o projeto educativo e de formação da criança e do adolescente.

O momento atual, descreve Silva (2010, p. 446), direciona para uma "encruzilhada": se, por um lado, a situação requer a construção de relações formalmente mais estreitas entre a família e a escola, na prática, se percebe que esse diálogo nunca esteve tão distante, principalmente quando envolve escola pública e pais/familiares de estudantes de baixa renda. É possível, contudo, construir uma ponte entre tais instituições e estabelecer um diálogo em prol de um objetivo comum, sem que haja, porém, um processo de culpabilização ou animosidade?

A seguir, algumas sugestões nesse aspecto e o exemplo de ações bem-sucedidas desenvolvidas por uma equipe multidisciplinar da Secretaria de Educação do município de Lagoa de Dentro, localizada no limiar entre o Agreste e a Zona da Mata paraibana.

Relação família-escola: é possível um diálogo construtivo?

Não obstante, a presente pesquisa não visa esgotar o tema em questão. Contudo, apresentar-se-ão algumas ações que podem ser úteis na construção dessa relação. Assim, para se estabelecer um diálogo construtivo entre essas duas esferas (família e escola), é preciso, primeiramente, reconhecer a posição de desvantagem em que se encontra a família. Dessa forma, é importante que a iniciativa de contato parta da escola, isto é, a instituição precisa assumir uma postura ativa.

Ao contrário, para que haja o desenvolvimento desta relação, a escola não deve adotar um comportamento passivo, de espera, aguardando ou que os pais/responsáveis lhes procurem, ou procurando-os apenas em situações específicas ou extremas, reforçando o comportamento de culpabilização dos pais/responsáveis pelos problemas com o menor na escola (mau comportamento, nota baixa etc.). 
A segunda sugestão é de que esse não pode ser um trabalho individual, pontual, isto é, não compete exclusivamente ao docente de sala de aula, ao coordenador, ao diretor, nem à instituição escolar. Trata-se de um trabalho em rede, em que todo o sistema trabalha em equipe e em conjunto, ou seja, cada instituição ampara a ação do outro. Um exemplo bem sucedido é o que está sendo desenvolvido, atualmente, na cidade de Lagoa de Dentro, município do Agreste paraibano, em que uma equipe multidisciplinar, formada por pedagogos e psicopedagogos, trabalha amparada pela Secretaria de Educação do município (que disponibiliza recursos e meios para que seja desenvolvida uma rede de trabalho), juntamente aos professores, diretores das escolas, coordenadores, e com o apoio, quando necessário, do conselho tutelar municipal e do Ministério Público Estadual.

Essa equipe multidisciplinar, além de visitar as escolas, inclusive às da zona rural (ou principalmente, já que, em geral, são as que possuem menos recursos), promovem encontros e treinamentos (contínuos) com os professores e profissionais da educação do município. Nesses encontros, ouvem-se as dificuldades locais de cada profissional/instituição, para então serem sugeridas as ações correspondentes. Eles são estimulados a ressaltarem características positivas de cada aluno dentro de sala de aula (Projeto "Faça três elogios por dia"). Além disso, são treinados para identificarem alunos em situações de vulnerabilidade e com dificuldade de aprendizagem. A direção da escola é incentivada a se aproximar da família desse aluno e ir conhecer o contexto social em que vivem.

Em um primeiro momento, tenta-se um encontro dentro da instituição, chamando-os para irem até a escola. Se, contudo, os pais/responsáveis se mantiverem indiferentes, reporta-se o caso à Secretaria de Educação. A equipe multidisciplinar, quando da resistência por parte da família do estudante, faz uma visita ao domicílio da criança/adolescente.

Em qualquer desses encontros, o contato com a família deve sempre buscar atender um apelo emocional e nunca de enfrentamento ou de culpabilização desses pais/responsáveis, já que eles próprios também se encontram, muitas vezes, em situação de pobreza e/ou extrema pobreza e possuem baixa escolaridade. A aproximação, portanto, deve ser muito mais no sentido de escutar com empatia e com cuidado o que eles têm a dizer, seus medos e preocupações, do que para repreendê-los por alguma omissão no acompanhamento escolar do educando.

Os frutos de tais ações ainda estão sendo colhidos, entretanto, já se percebe uma melhora no desenvolvimento escolar dos alunos, principalmente em itens como comportamento, concentração e frequência, conforme relato da psicopedagoga Déborah Kallyne Santos da Silva, das professoras-pedagogas Cláudia Costa dos Santos (orientadora educacional e presidente do conselho do CACS/FUNDEB) e Maria José de Andrade Silva (coordenadora pedagógica do Ensino Fundamental - séries iniciais), todas servidoras do Município de Lagoa de Dentro, em palestra realizada no dia 16 de agosto de 2018, no Campus IV/Mamanguape ${ }^{6}$.

6 I Roda de diálogos do projeto de extensão universitária "Família, escola e desenvolvimento de aprendizagem". Ocorrido no dia 16 de agosto de 2018, na sala da ADUF - PB/Campus IV, Mamanguape - Litoral Norte, das $15 \mathrm{~h}$ às $18 \mathrm{~h}$, na presença do professor e coordenador doutor Geraldo Alexandre de Oliveira Gomes, da bolsista extensionista Layze Cristine Maia Alves e da aluna colaboradora Ana Paula Taigy do Amaral. 
Portanto, para uma relação construtiva, a escola precisa ser integrada à comunidade, ter conhecimento dos problemas que acontecem dentro e entre a escola, ter uma rede de apoio onde possa reportá-los, no intuito de, em parceria com outros órgãos do Estado, tentar, se não os resolver, amenizar seus impactos na aprendizagem da criança/adolescente.

\section{Considerações finais}

Este artigo é resultado de análises e reflexões produzidas a partir de experiências decorrentes do projeto de extensão universitária (UFPB/Campus IV) "Família, escola e desenvolvimento de aprendizagem", que teve como fim trabalhar com pais/responsáveis de crianças/adolescentes matriculados no II ciclo do ensino fundamental de duas escolas da rede pública de ensino do município de Mamanguape-PB, com o objetivo de despertar a relevância do acompanhamento familiar para o desenvolvimento de aprendizagens.

Apesar de a proposta inicial, no decorrer da experiência, percebeu-se a relação crítica que se estabelece entre a escola pública e os familiares dos estudantes de baixa renda. Assim, partindo de uma pesquisa bibliográfica sobre o tema, à luz da leitura de Saviani (1997), Bourdieu e Passeron (1992), Pedro Silva (2010), analisou-se o que está por trás da relação família-escola, isto é, a função social, a natureza simbólica das instituições, as transformações sociais que as influenciaram/influenciam e, por fim, reuniram-se algumas sugestões de ações que são consideradas benéficas para o estreitamento desse vínculo.

Quanto a este aspecto, concluiu-se que é preciso que a escola focalize seu olhar crítico em si e que crie condições para que os pais/responsáveis participem do trabalho escolar. Para tanto, é necessário que a mesma adote uma postura ativa e procure estabelecer uma relação de confiança com a família e com a comunidade na qual está inserida.

No entanto este trabalho não pode ser desenvolvido de forma unitária, exclusiva pelo professor, pela coordenação ou pela direção da escola, porém, em conjunto, com o amparo e o suporte de secretarias de educação, e até com o apoio de outras instituições públicas (Conselho Tutelar e Ministério Público), considerando sempre o melhor para o desenvolvimento da criança e do adolescente.

\section{Referências}

BOURDIEU, Pierre; PASSERON, Jean-Claude. A reprodução: elementos para uma teoria do sistema de ensino. Rio de Janeiro: Livraria Francisco Alves Editora, 1992.

BRASIL. [Constituição (1988)]. Constituição da República Federativa do Brasil. Brasília: Congresso Nacional, 1988. Disponível em: <http://www.planalto.gov.br/ccivil_03/constituicao/constituicao.htm>. Acesso em: 20 jul. 2019.

BRASIL. Lei no 9.394, de 20 de dezembro de 1996. Estabelece as diretrizes e bases da educação nacional. Disponível em: <http://www.planalto.gov.br/ccivil_03/leis/19394.htm>. Acesso em: 26 de jul. 2018. 
BRASIL. Lei no 11.494, de 20 de junho de 2007. Regulamenta o Fundo de Manutenção e Desenvolvimento da Educação Básica e de Valorização dos Profissionais da Educação - FUNDEB. Disponível em: <http://www.planalto.gov. br/ccivil_03/_ato2007-2010/2007/lei/111494.htm>. Acesso em: 18 mar. 2020.

IBGE. Instituto Brasileiro de Geografia e Estatística - 2017a. Panorama das cidades/Brasil/Paraíba/Mamanguape/Trabalho e Rendimento. [Documento eletrônico] Disponível em: <https://cidades.ibge.gov.br/brasil/pb/ mamanguape/panorama>. Acesso em: 23 jul. 2018.

IBGE. Instituto Brasileiro de Geografia e Estatística - 2019. Pesquisa Nacional por Amostra de Domicílios Contínua (PNAD Contínua) - Educação 2018. Publicado em: 19 jun. 2019. Disponível em: < https://agenciadenoticias. ibge.gov.br/media/com_mediaibge/arquivos/00e02a8bb67cdedc4fb22601ed264c00.pdf >. Acesso em: 22 jul. 2019. IBGE. Instituto Brasileiro de Geografia e Estatística - 2017b. Rendimento nominal mensal domiciliar per capita da população residente, segundo as Unidades da Federação. 2017. Disponível em: <ftp://ftp.ibge.gov.br/Trabalho_e_Rendimento/Pesquisa_Nacional_por_Amostra_de_Domicilios_continua/Renda_domiciliar_per_capita/ Renda_domiciliar_per_capita_2017.pdf >. Acesso em: 31 jul. 2018.

INEP. Instituto Nacional de Estudos e Pesquisas Educacionais Anísio Teixeira - 2015a, 2017a. IDEB - Resultados e Metas 2015, 2017. Disponível em: <http://ideb.inep.gov.br/resultado/>. Acesso em: 18 mar. 2020.

INEP. Instituto Nacional de Estudos e Pesquisas Educacionais Anísio Teixeira. Relatório do 2o Ciclo de Monitoramento das Metas do Plano Nacional de Educação - 2018. Brasília, DF: Inep, 2018b. Disponível em: <file://C:/ Users/Ana/Downloads/pne_relatorio_ciclo_2_monitoramento_metas_pne_bienio_2018.pdf>. Acesso em: 22 jul. 2019.

INEP. Instituto Nacional de Estudos e Pesquisas Educacionais Anísio Teixeira - 2014, 2015b, 2016, 2017b, $2018 \mathrm{a}$. Sinopses Estatísticas da Educação Básica 2014, 2015, 2016, 2017, 2018. Disponível em: <http://portal.inep.gov. br/web/guest/sinopses-estatisticas-da-educacao-basica>. Acesso em: 18 mar. 2020.

MEC. Ministério da Educação. FNDE - Fundo Nacional de Desenvolvimento da Educação. Dados Estatísticos: Matrículas, coeficientes de distribuição de recursos e receita anual prevista por Estado e Município - 2015b, 2016b, 2017b, 2018b, 2019b. Disponível em: <https://www.fnde.gov.br/index.php/financiamento/fundeb/area-para-gestores/dados-estatisticos>. Acesso em: 18 mar. 2020.

MEC. Ministério da Educação. FNDE - Fundo Nacional de Desenvolvimento da Educação. Dados Estatísticos: Valor anual por aluno estimado, no âmbito do Distrito Federal e dos Estados, e estimativa de receita do Fundeb - 2015a, 2016a, 2017a, 2018a, 2019a. Disponível em: <https://www.fnde.gov.br/index.php/acesso-a-informacao/ institucional/legislacao/itemlist/category/164-portaria?start=70>. Acesso em: 18 mar. 2020.

OCDE. Organização para a Cooperação e Desenvolvimento Econômico - 2016. Coutry Note: Programme for international student assessment (PISA) - Results from PISA 2015. Brasil. Disponível em: <http://www.oecd.org/ pisa/PISA-2015-Brazil-PRT.pdf > . Acesso em: 24 jul. 2018.

OCDE. Organização para a Cooperação e Desenvolvimento Econômico - 2019. Coutry Note: Programme for international student assessment (PISA) - Results from PISA 2018. Brasil. Disponível em: <https://www.oecd. org/pisa/publications/PISA2018_CN_BRA.pdf>. Acesso em: 18 mar. 2020.

GOODE, William; HATT, Paul K. Métodos em pesquisa social. São Paulo: Nacional, 1973.

MAGALHÃES, António Manuel; STOER, Stephen Ronaldo. Inclusão Social e "Escola Reclamada”. In: RODRIGUES, David. (Org.). Inclusão e educação: doze olhares sobre a educação inclusiva. São Paulo: Summus, 2006. p. 64-84.

MARTINS, Gilberto de Andrade; LINTZ, Alexandre. Guia para elaboração de monografias e trabalhos de conclusão de curso. São Paulo: Atlas, 2002. 
MONTEIRO, Adalberto. Conquistas e desafios do movimento LGBT. Revista Princípios, São Paulo, ed. 96, p. 5153, jun./jul., 2008. Disponível em: <http://revistaprincipios.com.br/artigos/96/cat/714/conquistas-e-desafios-do-movimento-lgbt-.html>. Acesso em: 26 ago. 2019.

OLIVEIRA, Cynthia Bisinoto Evangelista de; MARINHO-ARAUJO, Claisy Maira. A relação família-escola: intersecções e desafios. Estudos de Psicologia, Campinas, v. 27, n. 1, p. 99-108, 2010. Disponível em: < http://www. scielo.br/pdf/estpsi/v27n1/v27n1a12.pdf>. Acesso em: 21 jul. 2019.

RICHARDSON, Roberto. et al. Pesquisa social: métodos e técnicas. São Paulo: Atlas, 1999.

SASSAKI, Alex. et al. Por que o Brasil vai mal no Pisa? Uma Análise dos Determinantes do Desempenho no Exame. Policy Paper, São Paulo, n. 31, p. 1-24, jun. 2018. Disponível em: < https://www.insper.edu.br/wp-content/ uploads/2018/08/Por-que-Brasil-vai-mal-PISA-Analise-Determinantes-Desempenho.pdf >. Acesso em: 24 jul. 2019.

SAVIANI, Dermeval. Escola e democracia. Campinas: Autores Associados, 1997.

SILVA, Pedro. Análise sociológica da relação escola-família: um roteiro sobre o caso português. Revista do Departamento de Sociologia da FLUP, Porto, v. 20, p. 443-464, 2010. Disponível em: < http://ler.letras.up.pt/uploads/ ficheiros/8812.Pdf >. Acesso em: 22 jul 2019.

YIN, Robert. Estudo de caso: planejamento e métodos. Porto Alegre: Bookman, 2005.

Recebido em: 24/09/2019

Aceito em: 26/03/2020 